\title{
Water in Mantle Xenoliths: Magma Ascent Too Slow to Preserve Lithospheric Water Concentrations
}

\section{WILLIAM HENRY TOWBIN AND TERRY A PLANK}

Lamont-Doherty Earth Observatory

Presenting Author: htowbin@1deo.columbia.edu

Do peridotite xenoliths preserve their mantle water concentrations or instead equilibrate with their host magma during ascent? A problem in resolving this question is that xenolith studies seldom constrain the volatile concentration and ascent history of the host magma. This study aims to provide such context for peridotite xenoliths erupted from a scoria cinder cone north of the Grand Canyon.

Clinopyroxene, the slowest phase in the xenolith to diffuse water, exhibits flat core profiles containing 500-600 ppm H2O as determined by SIMS. Zonation only occurs within $50 \mu \mathrm{m}$ of the rims, reflecting late stage water loss in the conduit as the magma degasses. The core plateau concentrations agree with expected equilibrium partitioning given the undegassed water concentration $(3 \mathrm{wt} \%)$ in the host magma measured in melt inclusions. To determine whether this agreement reflects complete exchange between xenolith and host magma during ascent, we apply multiple diffusion chronometers to determine the time for xenolith ascent. Olivine zonation profiles for $\mathrm{Fe}-\mathrm{Mg}$, $\mathrm{Ca}$ and $\mathrm{Ni}$ were measured in xenocrysts separated from the host scoria (derived from xenolith disaggregation) and olivines adjacent to melt pockets within the xenoliths. Magmatic overgrowths on the xenocrystic olivines provide mixing-toeruption timescales of $0.5-4$ days. This is a minimum timescale for xenolith ascent, since disaggregation could occur in the shallow conduit. Olivines adjacent to isolated melt pockets, formed within the xenolith in-situ after heating, have diffusion profiles that developed $8+/-2$ days prior to eruption. Both of these timescales are longer than that expected for water equilibration. Using the diffusivities in Ferris et al. (2016) and a temperature of $1200^{\circ} \mathrm{C}$ for the host magma, ascent from $60 \mathrm{~km}$ must occur in under $3 \mathrm{hrs}$ for $0.5 \mathrm{~mm}$ clinopyroxenes to preserve core water concentrations. The flat and equilibrated zonation profiles that we observe in pyroxene cores require longer times, approaching $37 \mathrm{hrs}$, but still considerably less than the week required to develop the olivine profiles adjacent to the xenolith melt pockets. Thus, we conclude that the high temperatures and relatively slow ascent of alkali basalts that erupt in cinder cones are not favorable to the preservation of mantle water in xenoliths. 